\title{
The application of unmanned aerial vehicle in agriculture
}

\section{Zastosowanie bezzałogowych statków powietrznych w rolnictwie}

\author{
Jolanta Kowalska1*, Magdalena Jakubowska², Andrzej Wójtowicz³ , Dariusz Drożdżyński
}

\section{Summary}

Unmanned aerial vehicles (UAVs) equipped with optical sensors are used more frequently in research aiming at solving numerous problems occurring in agriculture. Particularly noteworthy is the use of these devices to identify plant threats caused by pests. In addition, they are helpful in making decisions on the regulation of nutrient content in soil, irrigation of pastures and arable fields, and determining the date of crop harvesting and loses in yield. The examples cited in this publication indicate unquestionably the huge potential of integration of UAVs with optical sensors that record radiation in the optical range (350-3000 nm). Thermographic and fluorescent sensors are also very popular. In the near future, UAVs will play a key role in improving the profitability of agricultural production.

Key words: unmanned aerial vehicle (UAVs), vegetation indices

\section{Streszczenie}

Bezzałogowe statki powietrzne wyposażone w czujniki optyczne znajdują coraz powszechniejsze zastosowanie w badaniach ukierunkowanych na rozwiązywanie licznych problemów występujących w rolnictwie. Na szczególną uwagę zasługuje wykorzystanie tych urządzeń do identyfikacji zagrożeń roślin powodowanych przez agrofagi. Poza tym są pomocne przy podejmowaniu decyzji dotyczących regulacji zawartości składników pokarmowych w glebie, nawadniania pastwisk i pól uprawnych oraz określania terminu zbioru płodów rolnych i szkód w rolnictwie. Przytoczone w niniejszej publikacji przykłady wskazują bezspornie na ogromny potencjał integracji bezzałogowych statków powietrznych z czujnikami optycznymi, które rejestrują promieniowanie z zakresu optycznego (350-3000 nm), a wśród nich dużą popularnością cieszą się także czujniki termograficzne i fluorescencyjne. W niedalekiej przyszłości bezzałogowe statki powietrzne odegrają z pewnością kluczową rolę w poprawie opłacalności produkcji rolniczej.

Słowa kluczowe: bezzałogowy statek powietrzny, wskaźniki wegetacji roślin

\footnotetext{
Instytut Ochrony Roślin - Państwowy Instytut Badawczy

${ }^{1}$ Zakład Metod Biologicznych i Rolnictwa Ekologicznego

${ }^{2}$ Zakład Monitorowania i Sygnalizacji Agrofagów

${ }^{3}$ Zakład Mykologii

${ }^{4}$ Zakład Badania Pozostałości Środków Ochrony Roślin

Władysława Węgorka 20, 60-318 Poznań

*corresponding author: j.kowalska@iorpib.poznan.pl

ORCID: 0000-0002-0588-7355
} 


\section{Wstęp / Introduction}

Bezzałogowy statek powietrzny (BSP) nie wymaga do lotu załogi obecnej na pokładzie oraz nie ma możliwości zabierania pasażerów. Pilotowany jest zdalnie lub wykonuje lot autonomicznie. Wyróżnia się pięć kategorii bezzałogowych statków powietrznych według ich masy: bardzo ciężkie (> $2000 \mathrm{~kg})$, ciężkie (200-2000 kg), średnie (50-200 kg), lekkie $(5-50 \mathrm{~kg})$, bardzo lekkie $(<5 \mathrm{~kg})$, a według pułapu dzieli się je na trzy kategorie: niską ( $<1000$ m n.p.m.), średnią (1000-10 000 m n.p.m.) i wysoką (> 10000 m n.p.m.) (Agostino i wsp. 2016).

Bezzałogowe statki powietrzne znajdują coraz szersze zastosowanie do celów wojskowych i cywilnych. Wśród zastosowań cywilnych należy wymienić monitorowanie bezpieczeństwa publicznego, nadzór ruchu, monitorowanie zjawisk atmosferycznych, badanie użytkowania gruntów $\mathrm{w}$ regionach wiejskich i miejskich oraz monitorowanie lasów i pól uprawnych. Przydatność bezzałogowych statków powietrznych jest wypadkową charakterystyk technicznych statków, takich jak prędkość lotu, maksymalny pułap, udźwig itp. oraz możliwości zainstalowanych na ich pokładach narzędzi, wśród których czujniki optyczne odgrywają kluczową rolę. Zadaniem tych czujników jest rejestracja odbitego promieniowania elektromagnetycznego od badanych obiektów. Właściwości obiektu, takie jak kształt, kolor czy szorstkość powierzchni decydują w dużym stopniu o własnościach spektralnych obiektów i powierzchni, ale nie decydują o ilości odbijanego od niego promieniowania. Wielkość promieniowania docierającego do czujnika pozwala na wygenerowanie krzywej spektralnej, definiowanej jako charakterystyka współczynnika odbicia w zależności od długości fali. Współczynnik odbicia światła - reflektancja, jest zależny od barwników zawartych w roślinach oraz od struktury komórkowej i zawartości wody, dlatego na podstawie jego wartości można ocenić poziom zdrowotności rośliny. Rośliny słabo odbijają światło w zakresie światła widzialnego, o długości od 400 do $700 \mathrm{~nm}$. Różnice w poziomie reflektancji, w zależności od stanu roślin można zauważyć w zakresie podczerwieni (powyżej 700 nm) (Mazur i Chojnacki 2017). Dzięki niezależnemu rejestrowaniu wybranych, wąskich pasm światła przez kamery multispektralne oraz odpowiednim kalkulacjom różnicowym tych pasm, możliwe jest pozyskanie fotomap stanu roślin, które można wykorzystać do podjęcia decyzji o rodzaju zabiegu (Candiago i wsp. 2015).

Krzywa spektralna zielonej roślinności charakteryzuje się następującymi właściwościami: stosunkowo silną absorpcją w zakresach niebieskim, czerwonym i środkowej podczerwieni oraz relatywnie wysokim odbiciem w zakresie zielonym i wysokim odbiciem w zakresie bliskiej podczerwieni. Charakterystyczne dla roślin zjawisko występowania dużego kontrastu pomiędzy odbiciem promieniowania widzialnego i promieniowania z zakresu bliskiej pod- czerwieni, zostało wykorzystane przy opracowywaniu tzw. wskaźników roślinności, które definiowane są jako bezjednostkowe miary radiometryczne służące do oceny aktywności wegetacyjnej roślin. Najpopularniejszym wskaźnikiem roślinności jest NDVI (Normalized Difference Vegetation Index) ustalony przez Rouse'a i wsp. (1974) definiowany jako iloraz różnicy i sumy promieniowania z zakresu bliskiej podczerwieni i promieniowania czerwonego. NDVI jest wykorzystywany między innymi do monitorowania upraw roślin, szacowania ich biomasy i prognozowania wysokości plonów (Asrar i wsp. 1984; Wanjura i Hatfield 1987; Bausch 1993; Benefetti i Rossini 1993). Przydatność tego wskaźnika wykazano także dla oceny erozji gleby (Dejong 1994), monitorowania obiegu wody i energii (Wood i Lakshmi 1993) oraz do szacowania degradacji pastwisk (Dymond i wsp. 1992).

Spektakularne sukcesy wynikające $\mathrm{z}$ zastosowania wskaźnika NDVI na tak szeroką skalę stymulują wzmożenie wysiłków w celu opracowania nowych wskaźników wegetacyjnych, które w intencji ich autorów powinny dostarczyć pełniejszych informacji o badanych obiektach.

Charakterystykę najpowszechniej stosowanych wskaźników wegetacji roślin prezentują między innymi: Li i wsp. (2014), Wójtowicz i wsp. (2016) oraz Xue i Su (2017).

\section{Wykorzystanie bezzałogowych statków powietrznych w rolnictwie / Utilization of unmanned aerial vehicles in agriculture}

Przegląd literatury dotyczącej wykorzystania bezzałogowych statków powietrznych wyposażonych w czujniki optyczne dostarcza licznych przykładów potwierdzających tezę o ogromnym potencjale tych urządzeń w rozwiązywaniu problemów występujących w rolnictwie. Jednym $\mathrm{z}$ pierwszych zastosowań opartym na zróżnicowaniu w odbiciu światła od roślin różnych gatunków było wykorzystanie tej technologii do identyfikacji upraw rolniczych na obrazach UAV (Park i Park 2015). Ocena szkód w uprawach (Michez i wsp. 2016; Rutten i wsp. 2018) i monitorowanie rozwoju roślin (Reinecke i Prinsloo 2017), to kolejne przykłady ilustrujące przydatność tej technologii w rolnictwie. Niezwykle ważnym zadaniem realizowanym z wykorzystaniem bezzałogowych statków powietrznych jest mapowanie gleby dostarczające precyzyjnych informacji do wykorzystania przy ustalaniu płodozmianów, planu nawożenia i prognozowaniu plonów roślin uprawnych. Oprócz informacji o zasobności gleby do prognozowania plonów wykorzystuje się wyniki pomiarów spektralnych prowadzonych w okresie wegetacji roślin (Yu i wsp. 2016). Bezzałogowe statki powietrzne są używane również do lokalizacji chwastów (Hardin i wsp. 2007), monitorowania biomasy upraw (Hunt i wsp. 2005; Swain i wsp. 2010), mapowania wigoru winnic (Primicerio i wsp. 2012) i badania efektywności różnych 
zabiegów azotowych w uprawach (Hunt i wsp. 2005; Swain i wsp. 2007).

Interesujący przykład integracji bezzałogowego statku powietrznego z czujnikami optycznymi znaleźć można również w pracy Berniego i wsp. (2009), którzy wykazali przydatność obrazów pozyskiwanych za pomocą kamer hiperspektralnej i termicznej do wykrywania deficytu wodnego w uprawach. W przeprowadzonych badaniach autorzy uwzględnili oprócz pomiaru temperatury roślin, dwadzieścia dwa wskaźniki charakteryzujące odbicie światła od badanych roślin oraz dziesięć wskaźników fluorescencyjnych. Zarówno pomiary temperatury roślin, jak i odbicia światła oraz natężenia fluorescencji okazały się przydatne do oceny deficytu wodnego. Spośród badanych wskaźników najlepszymi okazały się te, które charakteryzują odbicie światła w zakresie widzialnym i bliskiej podczerwieni.

Wskaźniki roślinności znajdują również zastosowanie w prognozowaniu plonów roślin. Gong i wsp. (2018) wykazali przydatność wskaźników wegetacyjnych wykorzystywanych $\mathrm{w}$ połączeniu $\mathrm{z}$ informacjami o liczebności liści, uzyskiwanymi za pomocą kamery hiperspekteralnej zainstalowanej na pokładzie bezzałogowego statku powietrznego do szacowania plonu rzepaku. Najdokładniejsze pomiary uzyskano w tych badaniach w efekcie zastosowania następujących wskaźników: NDVI, Red Edge Chlorophyll Index (NDRE), Triangular Vegetation Index (TVI) i Soil Adjusted Vegetation Index (SAVI).

Obrazy pozyskane z wykorzystaniem czujników optycznych zainstalowanych na bezzałogowych statkach powietrznych znajdują również zastosowanie w badaniach ukierunkowanych na identyfikację patogenów roślin. Interesujące badania z tego zakresu prezentują Sugiura i wsp. (2016), którzy wykorzystali kamerę RGB bez podczerwieni i bezzałogowy helikopter. Oceniali oni przydatność tej technologii do szacowania odporności ziemniaka na Phytophthora infestans, sprawcę zarazy ziemniaka. W trakcie badań uzyskali 11 obrazów analizowanego pola, które po przetworzeniu wykorzystali do oszacowania powierzchni pod krzywą rozwoju choroby. Celem tych doświadczeń było porównanie powierzchni pod krzywą rozwoju choroby oszacowaną dwoma metodami: zaproponowaną przez autorów metodą przetwarzania obrazów oraz tradycyjną polegającą na określeniu porażenia roślin na podstawie obserwacji polowych. Zgodność obu metod oszacowana z wykorzystaniem współczynnika determinacji wynosiła 0,77. Uzyskany wynik wskazuje na przewagę metody opartej na przetwarzaniu obrazów nad pracochłonnym podejściem konwencjonalnym.

Kolejnym przykładem potwierdzającym możliwości zastosowania bezzałogowego statku powietrznego wyposażonego w czujnik optyczny do wykrywania chorób roślin są badania Garcia-Ruiz i wsp. (2013) ukierunkowane na identyfikację choroby zielenienia cytrusów. W przeprowadzonym doświadczeniu porównano wyniki obserwacji naziemnych z wynikami uzyskanymi w efekcie analizy zdjęć wykonanych z pokładu bezzałogowego statku powietrznego oraz z pokładu samolotu. W badaniach uwzględniono 6 długości fali oraz 7 wskaźników wegetacyjnych. Zgodność obserwacji polowych z wynikami pomiarów spektralnych przeprowadzonych z wykorzystaniem bezzałogowego stat$\mathrm{ku}$ powietrznego wynosiła od 67 do $85 \%$. Nieco gorsze wyniki wynoszące 61-74\% uzyskano przy porównaniu obserwacji naziemnych z pomiarami prowadzonymi z pokładu samolotu. Przeprowadzone badania stanowią potwierdzenie tezy o dużym potencjale bezzałogowych statków powietrznych do wczesnego wykrywania sprawców chorób, gwarantującego minimalizację zużycia środków ochrony roślin.

Ograniczanie zużycia środków ochrony roślin stanowiło również inspiracje dla zastosowań bezzałogowych statków powietrznych do prowadzenia zabiegów ochrony roślin. Należy podkreślić, że zaprojektowanie bezzałogowych statków powietrznych do tego celu było poważnym wyzwaniem z uwagi na konieczność uwzględnienia dodatkowego obciążenia oraz zapewnienia odpowiedniej mocy aplikatora środków ochrony roślin. Do tej roli szczególnie dobrze nadają się wielorotorowe statki powietrzne, które charakteryzują się dużą zwrotnością i nie wymagają dużej powierzchni do lądowania. Szczególnie zaawansowane prace nad wykorzystaniem tej technologii prowadzone są w Chinach (Zhigang i wsp. 2013; Qin i wsp. 2014; Ru i wsp. 2014; Ru i wsp. 2015). Przykładem ilustrującym zastosowanie bezzałogowych statków powietrznych do aplikacji pestycydów w Europie są badania Martinez-Guanter i wsp. (2019) nad zwalczaniem oliwkowej muszki owocowej (Bactrocera oleae) i pospolitej muszki owocowej (Drosophila melanogaster) w gajach oliwnych i cytrusowych w Hiszpanii. Na podstawie analizy uwzględniającej równomierność pokrycia liści, wydatku cieczy i znoszenia preparatu, badacze hiszpańscy wykazali przewagę bezzałogowego statku powietrznego nad konwencjonalnym opryskiwaczem. Dodatkowym ważnym aspektem stosowania zabiegów ochrony roślin z pokładu bezzałogowych statków powietrznych, na który zwracają uwagę Martinez-Guanter i wsp. (2019) jest uniknięcie ugniatania gleby występującego powszechnie przy zabiegach konwencjonalnych.

$\mathrm{Na}$ zalety aplikacji środków ochrony roślin z pokładu bezzałogowych statków powietrznych wskazują również badania Gilesa i Billinga (2015), którzy ocenili efekty tego rozwiązania w oparciu o wyniki doświadczeń realizowanych w winnicach zlokalizowanych w Kalifornii. Na podstawie przeprowadzonych eksperymentów stwierdzili, że jakość aplikacji z pokładu bezzałogowego statku powietrznego nie ustępuje metodzie konwencjonalnej, a zapewnia przewagę pod względem wydajności. Natomiast Berner i Chojnacki (2017) stwierdzili korzystny wpływ działania wirników drona na precyzyjną aplikację środka biologicznego zawierającego entomopatogenne nicienie.

W Polsce stosowanie bezzałogowych statków powietrznych do aplikacji środków ochrony roślin jest prawnie zabronione. Nie stanowi to jednak przeszkody 
w rozwoju firm proponujących coraz szerszy zakres usług, wśród których oferta skierowana do rolników nabiera coraz większego znaczenia. Zdalnie sterowane bezzałogowe systemy lotnicze (BSP) są coraz częściej wykorzystywane w rolnictwie do zdalnej kontroli obszarów upraw, wykrywania problemów w uprawie i na polu oraz precyzyjnego określania szkód (powodowanych np. przez zwierzynę łowną, suszę i mróz) w uprawach rolniczych. Chociaż technicznie są w stanie transportować i aplikować agrochemikalia, zastosowanie BSP do takich misji jest znacznie mniej powszechne ze względu na obecne ograniczenia regulacyjne i projektowe. Głównymi barierami prawnymi są zakazy opryskiwania z powietrza, które zostały wprowadzone w życie ze względu na obawy związane z ochroną środowiska oraz przepisy antyterrorystyczne, które zasadniczo uniemożliwiają przenoszenie ładunków użytecznych przez drony. W wielu krajach prowadzone są jednak prace nad zmianą przepisów umożliwiających ich wykonywanie ze względu na potencjalne korzyści, które się z tym wiążą: możliwość opryskiwania wyższych roślin (kukurydza), dostęp do trudnego terenu, miejscowe wykonywanie zabiegów na obszarach wymagających interwencji z zachowaniem zasad bezpieczeństwa dla środowiska z uwagi na mniejsze wydatkowanie pestycydów i nawozów (www. adama.com).

\section{Aspekt ekonomiczny i inne korzyści / Economical point and other benefits}

Potencjał światowego rynku komercyjnych zastosowań technologii dronowych (Duszczyk 2016) przedstawia się następująco: infrastruktura (nadzór inwestycji, utrzymywanie, inwentaryzacja) - 45,2 mld dolarów; rolnictwo (monitoring upraw, analiza zasobności gruntu, ocena kondycji upraw) - 32,4 mld dolarów; transport (dostawa towarów, żywności, leków) - 13,0 mld dolarów; bezpieczeństwo cywilne (monitoring granic obiektów, reagowanie na zagrożenia) - 10,5 mld dolarów; media, rozrywka (film i fotografia, reklama, rozrywka, pokazy, efekty specjalne) - 8,8 mld dolarów; ubezpieczenia (ocena ryzyka, analiza roszczeń, wykrywanie oszustw) - 6,8 mld dolarów; telekomunikacja (utrzymanie, przesyłanie sygnałów telekomunikacyjnych) 6,3 mld dolarów; górnictwo (planowanie i ocena wpływu na środowisko) - 4,3 mld dolarów.

Zastosowania badawcze teledetekcji w rolnictwie precyzyjnym przy użyciu dronów są liczne i obejmują techniki: wykrywania stresu wodnego w roślinach związanego z suszami, stresu azotowego, zachwaszczenia, detekcji chorób grzybowych oraz detekcji owadów - szkodników na polach. Teledetekcja wykazała zdolność do identyfikacji tych defektów, z dokładnością od 50 do $80 \%$ w odniesieniu do występowania stresu odżywczego, 46 do $82 \%$ w odniesieniu do uszkodzeń roślin spowodowanych przez owa- dy, 57 do $97 \%$ w przypadku defektów roślin spowodowanych przez patogeny roślin i 75 do $92 \%$ w przypadku występowania chwastów w porównaniu do naziemnej oceny stanu fitosanitarnego pól uprawnych. Precyzja zależy od etapu wzrostu uprawy i poziomu stresu roślin występującego podczas uprawy (Mulla i Miao 2016).

Potencjalne korzyści wynikające ze stosowania do nawożenia i ochrony roślin precyzyjnie aplikujących zdalnie sterowanych lub autonomicznych urządzeń są łatwe do oszacowania. Zgodnie $\mathrm{z}$ badaniami wykonanymi dla upraw kukurydzy w stanie Iowa (USA) dzięki precyzyjnej aplikacji nawozów zredukowano ich zużycie w zależności od monitorowanego pola od 30 do $40 \%$. Oszacowany wzrost plonów wyniósł średnio od 300 do $350 \mathrm{~kg} /$ ha przy obniżeniu kosztów nawozów o 1/3. Heisel i wsp. (1999) wykazali, że zastosowanie odpowiedniej technologii rozpylania wraz ze wsparciem systemów decyzji dla precyzyjnego stosowania herbicydów daje potencjalne oszczędności herbicydów w granicach od 30 do 75\%. Wysoki potencjał zgromadzonych przez bezzałogowe statki powietrzne (BSP) informacji pozwala rolnikowi na ich wykorzystanie do wykonania niektórych zabiegów polowych, takich jak opryskiwanie, również w połączeniu z jednoczesnym nawożeniem preparatami nalistnymi. W przypadku zlokalizowania ognisk choroby lub występowania szkodników, dzięki możliwościom identyfikacji zagrożenia, można dobrać odpowiedni pestycyd i błyskawicznie zastosować opryskiwanie interwencyjne. Aplikacja nie odbywa się na całej powierzchni pola, jak ma to miejsce w przypadku typowego opryskiwania z jeżdżącego sprzętu naziemnego, ale punktowo np. tylko na $25 \%$ powierzchni pola, co daje łatwe do policzenia oszczędności. Innym aspektem jest szybkość, z jaką przy pomocy BSP można wykonać zabieg oraz koszty pracownicze. Dla przykładu: obecnie stosowana do opryskiwania kukurydzy konwencjonalna maszyna rolnicza w ciągu godziny może wykonać ten zabieg na powierzchni 11 ha pola, tymczasem latającym dronem w tym samym czasie można by przeprowadzić opryskiwanie aż 80 ha pola. Kolejny pozytywny aspekt użycia bezzałogowców to oszczędność na zabiegach opryskiwania - może to być kluczowym argumentem dla rolników, którzy nie są pewni inwestycji w drony. Firma Yamaha (www.yamahamotorsports.com/motorsports/pages/precision-agriculture) wychodzi temu naprzeciw - nie trzeba od razu inwestować w drona i kurs obsługi. Firma ta planuje świadczyć usługi opryskiwania np. w kwocie 250 \$ za hektar pola w przypadku opryskiwania winnic. Po przeliczeniu ręcznej pracy i czasu poświęconego na ten cel, jest to usługa $40 \%$ tańsza od klasycznego opryskiwania. Łatwo zatem przeliczyć to na konkretne oszczędności w przypadku pól liczących sobie tysiące hektarów (Zawadzak 2016). Dodatkowo do obsługi drona wystarczy jeden pracownik. Praktycznie wyeliminowane jest narażenie rolnika na środki chemiczne aplikowane na polu. W zasadzie do tej pory nie znaleziono 
lepszego sposobu, by zabiegi opryskiwania pól były bezpieczniejsze dla ludzi wykonujących te zabiegi. Operator drona stoi zwykle $\mathrm{z}$ dala od miejsca, w którym rozpylane są pestycydy, więc w żaden sposób nie wpływa to już na jego zdrowie. Oczywiście, należy wziąć pod uwagę ograniczenia związane $\mathrm{z}$ dostarczeniem potrzebnej do oblotów dronem energii oraz doliczyć czas powrotu BSP do stanowiska kierowania lotem, wymiany akumulatorów i uzupełnienia preparatów ochronnych i/lub nawozowych. Precyzyjna aplikacja nawozów i środków ochrony roślin jest również istotna dla kondycji środowiska, bioróżnorodności, czy też zanieczyszczenia pozostałościami substancji czynnych lub stopnia eutrofizacji wód.

Możliwości wykorzystania dronów w rolnictwie nie tylko dotyczą określenia stanu fitosanitarnego na polach, czy też określenia wielkości powierzchni gospodarstwa lub precyzyjnego nawożenia, ale także mogą odnosić się do oceny szkód. Oceny szkód w rolnictwie można było dokonać szacunkowo, stosując szereg subiektywnych kryteriów. Przekształcenie polskiego rolnictwa w kierunku wielohektarowych gospodarstw generuje potrzebę zastosowania nowych technik oceny stanu upraw (Głębocki i Mirosław 2013). Pojawiła się koncepcja zastosowania bezzałogowych statków powietrznych do identyfikacji i określenia wielkości ponoszonych strat $\mathrm{w}$ gospodarowaniu związanych $\mathrm{z}$ precyzyjnym określaniem szkód w uprawach rolnych. Ta koncepcja odnosi się do bezpośredniej likwidacji szkód w tym sensie, że likwidatorzy znajdują się w „,centrach likwidacji” i za pomocą obrazu 3D oszacowują szkody w uprawach. Dzięki temu następuje ograniczenie tzw. uproszczonych ścieżek likwidacji szkód poprzez: szybką rejestrację szkód, szybszą procedurę likwidacji technicznej (oględzin szkody), sprawną likwidację merytoryczną (sprawdzenie: pokrycia ubezpieczeniowego, okresu ochrony ubezpieczeniowej, opłacenia składki), szybszą decyzję (zatwierdzenie szkody i przekazanie jej do wypłaty bądź odmowy) (Matusiewicz 2012). Wizualizacja przestrzenna pozwala bardzo szybko znaleźć zależności, określić potencjalny zakres szkód i sprawnie oszacować straty.

\section{Podsumowanie / Synthesis}

Przytoczone w niniejszej pracy wyniki badań i przykłady komercyjnych zastosowań bezzałogowych statków powietrznych wyposażonych w czujniki optyczne wskazują na ogromne możliwości stosowania tej technologii w rolnictwie. Termografia, pomiary fluorescencji chlorofilu i techniki hiperspektralne pozwalają na wykrywanie stresów roślin i identyfikowanie ich przyczyn. Najważniejszymi zaletami wynikającymi z integracji bezzałogowych statków powietrznych z czujnikami optycznymi są: bezinwazyjność, oszczędność i szybkość pozyskiwania informacji. Ta ostatnia cecha jest szczególnie ważna $\mathrm{w}$ odniesieniu do monitorowania nasilenia występowania chorób i szkodników roślin uprawnych. Wykrycie choroby lub szkodnika we wczesnym stadium rozwojowym daje bowiem większe szanse na ograniczenie strat w plonie roślin.

$\mathrm{Z}$ uwagi na to, że potencjał integracji bezzałogowych statków powietrznych z czujnikami optycznymi nie został jeszcze w pełni zbadany, należy oczekiwać w najbliższej przyszłości intensyfikacji badań ukierunkowanych na poszukiwanie nowych zastosowań tych technologii i ulepszenie dotychczasowych. Szczególnie obiecujące dla producentów rolnych wydaje się połączenie nieinwazyjnych metod optycznych realizowanych z wykorzystaniem bezzałogowych statków powietrznych z systemami wspomagającymi podejmowanie decyzji, wśród których na szczególną uwagę zasługują te, które dotyczą ochrony roślin.

Jednakże pomimo bezspornych zalet bezzałogowych statków powietrznych nie obserwuje się powszechnego zainteresowania producentów rolnych tymi rozwiązaniami. Jednocześnie cały czas trwają badania ukierunkowane na poprawę jakości i dokładności przetwarzania obrazów, zwiększenia zasięgu lotów oraz obniżenie kosztów oferowanych usług, co w niedalekiej przyszłości doprowadzi z pewnością do radykalnego zwiększenia kręgu odbiorców zastosowań tej technologii w rolnictwie.

\section{Literatura / References}

Agostino S., Mammone M., Nelson M., Zhou T. 2016. Classification of unmanned Aerial vehicles. Mechanical Engineering. http:// web.archive.org/web/20121021021237/http://personal.mecheng.adelaide.edu.au/maziar.arjomandi/aeronautical\%20engineering\%20projects/2006/group9.pdf [dostęp: 26.06.2019].

Asrar G., Fuchs M., Kanemasu E.T., Hatfield J.L. 1984. Estimating absorbed photosynthetic radiation and leaf area index from spectral reflectence in wheat. Agronomy Journal 76 (2): 300-306. DOI: 10.2134/agronj1984.00021962007600020029x.

Bausch W.C. 1993. Soil background effects on reflectance-based crop coefficients for corn. Remote Sensing of the Environment 46 (2): 213-222. DOI: 10.1016/0034-4257(93)90096-G.

Benefetti R., Rossini P. 1993. On the use of NDVI profiles as a tool for agricultyral statistics: The case of wheat yield estimates and forecast in Emilia Romagna. Remote Sensing of the Environment 45 (3): 311-326. DOI: 10.1016/0034-4257(93)90113-C.

Berner B., Chojnacki J. 2017. Influence of the air stream produced by the drone on the sementation of the sprayed liquid that contains entomopathogenic nematodes. Journal of Research and Applications in Agricultural Engineering 62 (3): $26-29$.

Berni J.A.J., Zarco-Tejada P.J., Suarez L., Fereres E. 2009. Thermal and narrowband multispectral remote sensing for vegetation monitoring from an unmanned aerial vehicle. IEEE Transactions on Geoscience and Remote Sensing 47 (3): 722-738. DOI: 10.1109/ TGRS.2008.2010457. 
Candiago S., Remondino F., De Giglio M., Dubbini M., Gattelli M. 2015. Evaluating multispectral images and vegetation indices for precision farming applications from UAV Images. Remote Sensing 7 (4): 4026-4047. DOI: 10.3390/rs70404026.

Dejong S.M. 1994. Derivation of vegetative variables from a landsat tm image for modeling soil erosion. Earth Surface Processes and Landforms 19 (2): 165-178. DOI: 10.1002/esp.3290190207.

Duszczyk M. 2016. Drony będą latać z krwią i lekami. Rzeczpospolita, 10 maja 2016.

Dymond J.R., Stephens P.R., Newsome P.F., Wilke R.H. 1992. Percentage vegetation cover of a degrading rangeland from SPOT. International Journal of Remote Sensing 13 (11): 1999-2007. DOI: 10.1080/01431169208904248.

Garcia-Ruiz F., Sankaran S., Maja J.M., Lee W.S., Rasmussen J., Ehsani R. 2013. Comparison of two aerial imaging platforms for identification of Huanglongbing-infected citrus trees. Computers and Electronics in Agriculture 91: 106-115. DOI: 10.1016/j. compag.2012.12.002.

Giles D.K., Billing R.C. 2015. Deployment and performance of a UAV for crop spraying. Chemical Engineering Transactions 44: 307-312. DOI: 10.3303/CET1544052.

Głębocki R., Mirosław T. 2013. Rozwój bezzałogowych statków latających jako szansa rozwoju gospodarczego oraz zagrożenie bezpieczeństwa państwa i obywateli. s. 17-24. W: Bezpieczeństwo i niezawodność w lotnictwie: rozwój lotnictwa w regionach: bezpieczne lata 2011-2013. Uniwersytet Technologiczno-Humanistyczny im. Kazimierza Pułaskiego, Radom.

Gong Y., Duan B., Fang S., Zhu R., Wu X., Ma Y. 2018. Remote estimation of rapeseed yield with unmanned aerial vehicle (UAV) imaging and spectral mixture analysis. Plant Methods 14: 70. DOI: 10.1186/s13007-018-0338-z.

Hardin P.J., Jackson M.W., Anderson V.J., Johnson R. 2007. Detecting squarrose knapweed (Centaurea virgata Lam. Ssp. squarrosa Gugl.) using a remotely piloted vehicle: a Utah case study. GIScience \& Remote Sensing 44 (3): 203-219. DOI: 10.2747/15481603.44.3.203.

Heisel T., Christensen S., Walter A.M. 1999. Whole-field experiments with site-specific weed management. W: Proceedings of the Second European Conference on Precision Agriculture (J.V. Stafford, red.). Odense, Denmark, 11-16 July, 1999, Part 2: $759-768$.

Hunt E.R., Cavigelli M., Daughtry C.S.T., McMurtrey J.E., Walthall C.L. 2005. Evaluation of digital photography from model aircraft for remote sensing of crop biomass and nitrogen status. Precision Agriculture 6 (4): 359-378. DOI: 10.1007/s11119005-2324-5.

Li X., Zhang Y., Bao Y., Luo J., Jin X., Xu X. 2014. Exploring the best hyperspectral features for LAI estimation using partial least squares regression. Remote Sensing 6 (7): 6221-6241. DOI: 10.3390/rs6076221.

Martinez-Guanter J., Agüera P., Agüera J., Pérez-Ruiz M. 2019. Spray and economics assessment of a UAV-based ultra-low-volume application in olive and citrus orchards. Precision Agriculture (online first). DOI: 10.1007/s11119-019-09665-7.

Matusiewicz J. 2012. Profilowane ścieżki. Miesięcznik Ubezpieczeniowy nr 11: 1-4.

Mazur P., Chojnacki J. 2017. Wykorzystanie dronów do teledetekcji multispektralnej w rolnictwie precyzyjnym. Technika Rolnicza Ogrodnicza Leśna 1: 25-28.

Michez A., Morelle K., Lehaire F., Widar J., Authelet M., Vermeulen C., Lejeune P. 2016. Use of unmanned aerial system to assess wildlife (Sus scrofa) damage to crops (Zea mays). Journal of Unmanned Vehicle Systems 4 (4): 266-275. DOI: 10.1139/juvs-20160014.

Mulla D.J., Miao Y. 2016. Land resources monitoring modelling and mapping with remote sensing. Precision Farming: 161-178. (online). https://www.downloaded by [China Agricultural Universits], [Yuxin Miao] at 19:39, [dostęp: 12.11.2015].

Park J.K., Park J. 2015. Crop Classification Using Imagery of Drone International Conference on Environmental Engineering and Remote Sensing (online). DOI: 10.2991/eers-15.2015.22.

Primicerio J., Gennaro S.F.D., Fiorillo E., Genesio L., Lugato E., Matese A. 2012. A flexible unmanned aerial vehicle for precision agriculture. Precision Agriculture (online first). DOI: 10.1007/s11119-012-9257-6.

Qin W., Xue X., Zhou L., Zhang S., Sun Z., Kong W., Wang B. 2014. Effects of spraying parameters of unmanned aerial vehicle on droplets deposition distribution of maize canopies. Transactions of the Chinese Society of Agricultural Engineering (online). DOI: 30.10.3969/j.issn.1002-6819.2014.05.007.

Reinecke M., Prinsloo T. 2017. The influence of drone monitoring on crop health and harvest size (online). DOI: 10.1109/ NEXTCOMP.2017.8016168.

Rouse J.W., Haas R.H., Schell J.A., Deering D.W. 1974. Monitoring vegetation systems in the great plains with ERTS. Proceedings, Third Earth Resources Technology Satellite-1 Symposium, Greenbelt: NASA SP-351, 3010-3017.

Ru Y., Jin L., Jia Z., Bao R., Qian X. 2015. Design and experiment on electrostatic spraying system for unmanned aerial vehicle. Nongye Gongcheng Xuebao/Transactions of the Chinese Society of Agricultural Engineering 31 (8): 42-47. DOI: 10.3969/j. issn.1002-6819.2015.08.007.

Ru Y., Jin L., Zhou H., Jia Z. 2014. Performance experiment of rotary hydraulic atomizing nozzle for aerial spraying application. Nongye Gongcheng Xuebao/Transactions of the Chinese Society of Agricultural Engineering 30 (3): 50-55. DOI: 10.3969/j. issn.1002-6819.2014.03.007.

Rutten A., Casaer J., Vogels M.F.A., Addink E.A., Vanden Borre J., Leirs H. 2018. Assessing agricultural damage by wild boar using drones: wild boar damage assessment. Wildlife Society Bulletin 42 (4): 568-576. DOI: 10.1002/wsb.916.

Sugiura R., Tsuda S., Tamiya S., Itoh A., Nishiwaki K., Murakami N., Shibuya Y., Hirafuji M., Nuske S. 2016. Field phenotyping system for the assessment of potato late blight resistance using RGB imagery from an unmanned aerial vehicle. Biosystems Engineering 148: 1-10. DOI: 10.1016/j.biosystemseng.2016.04.010.

Swain K.C., Jayasuriya H.P.W., Salokhe V.M. 2007. Suitability of low-altitude remote sensing images for estimating nitrogen treatment variations in rice cropping for precision agriculture adoption. Journal of Applied Remote Sensing 1 (1): 013547 (1 November 2007). DOI: 10.1117/1.2824287.

Swain K.C., Thomson S.J., Jayasuriya H.P.W. 2010. Adoption of an unmanned helicopter for low-altitude remote sensing to estimate yield and total biomass of a rice crop. Transactions of the ASABE 53 (1): 21-27. 
Wanjura D.F., Hatfield J.L. 1987. Sensivity of spectral vegetation indices to crop biomass. Transactions of the ASAE 30 (3): 0810-0816. DOI: 10.13031/2013.30479.

Wood E.F., Lakshmi V. 1993. Scaling water and energy fluxes in climate systems: three land-atmospheric modeling experiments. Journal of Climate 6 (5): 839-857. DOI: 10.1175/1520-0442.

Wójtowicz M., Wójtowicz A., Piekarczyk J. 2016. Application of remote sensing methods in agriculture. Communications in Biometry and Crop Science 11 (1): 31-50.

www.adama.com [dostęp: 26.06.2019].

www.yamahamotorsports.com/motorsports/pages/precision-agriculture [dostęp: 26.06.2019].

Xue J., Su B. 2017. Significant remote sensing vegetation indices: a review of developments and applications. Journal of Sensors, Volume 2017, Article ID 1353691, 17 ss. DOI: 10.1155/2017/1353691.

Yu N., Li L., Schmitz N., Tian L., Greenberg J.A., Diers B.W. 2016. Development of methods to improve soybean yield estimation and predict plant maturity with an unmanned aerial vehicle based platform. Remote Sensing of Environment 187: 91-101. DOI: 10.1016/j.rse.2016.10.005.

Zawadzak M. 2016. Drony rolnicze będą mieć największy udział w rynku. www.swiatdronow.pl/drony-rolnicze-najwiekszy-udzial-wrynku [dostęp: 24.02.2016].

Zhigang W., Yubin L., Hoffmann W.C., Yonghui W., Yongjun Z. 2013. Low altitude and multiple helicopter formation in precision aerial agriculture. American Society of Agricultural and Biological Engineers Annual International Meeting 2013 (online). DOI: 10.13031/aim.20131618681. 